\title{
Crescimento, acúmulo de nutrientes e produtividade da cultura da couve-flor
}

\author{
Renata Castoldi; Hamilton César de O Charlo; Pablo F Vargas; Leila T Braz \\ UNESP-FCAV, Dep to Produção Vegetal, Rod. Prof. Paulo Donato Castellane, s/n, 14884-900 Jaboticabal-SP; rcastoldi@gmail.com
}

\begin{abstract}
RESUMO
A couve-flor é uma das principais hortaliças cultivadas no Brasil. O conhecimento do crescimento e acúmulo de nutrientes pela cultura poderá ser útil no seu manejo e na adubação. Com o objetivo de determinar o acúmulo e a exportação de nutrientes pela cultura da couve-flor 'Verona', conduziu-se um experimento em solo, no período de 23 de fevereiro a 05 de junho de 2006. O delineamento do experimento foi em blocos casualizados com três repetições. $\mathrm{O}$ experimento constou inicialmente de 480 plantas divididas em três blocos. Para cada época de amostragem foram retiradas duas plantas por bloco. Foram realizadas cinco amostragens da parte vegetativa das plantas a cada 14 dias após o transplante e três amostragens das inflorescências a cada quatro dias, após o início de sua formação, sendo avaliado o crescimento da planta e o acúmulo de nutrientes nas inflorescências, no caule, nos limbos foliares e nos pecíolos. As plantas apresentaram crescimento e acúmulo de massa seca contínuos. O período de maior acúmulo de nutrientes foi do início da formação da inflorescência até a colheita. A ordem decrescente dos nutrientes acumulados pela cultura foi: $\mathrm{N}>\mathrm{K}>\mathrm{Ca}>\mathrm{S}>\mathrm{Mg}>\mathrm{P}>\mathrm{Fe}>\mathrm{Mn}>\mathrm{Zn}>\mathrm{B}>\mathrm{Cu}$. A exportação de nutrientes ( $\mathrm{g}$ por planta de macronutrientes e mg por planta para micronutrientes) pelas inflorescências foi de 3,50 de N; 0,296 de K; 0,06 de Ca; 0,290 de S; 0,032 de Mg; 0,249 de P; 2,08 de Fe; 0,375 de Mn; 1,01 de Zn; 1,45 de B e 0,07 de Cu.
\end{abstract}

Palavras-chave: Brassica oleracea var. botrytis, nutrição, solo.

\section{ABSTRACT}

Growth, nutrients accumulation and crop productivity of cauliflower

The cauliflower is one of the main vegetables grown in Brazil. The study of growth and nutrients accumulation by cauliflower could be useful for its fertilization. Therefore, a research was conducted in the field to determine the nutrients accumulation by 'Verona' cauliflower, from February 23 to June 5, 2006. The experiment consisted initially of 480 plants divided into three blocks. For each period two plants per block were collected. Five samples of the vegetative part were collected each 14 days after transplantation and three samples of inflorescences were collected every four days after the beginning of the cauliflower formation. Also, plant growth and nutrient accumulation in the inflorescences, stem, leaves and petioles were evaluated. Plants showed linear increase of growth and accumulation of dry matter. The greatest accumulation period occurred from the beginning of the inflorescence formation up to the harvest. The decreasing order of accumulated nutrients was: $\mathrm{N}>\mathrm{K}>\mathrm{Ca}>\mathrm{S}>\mathrm{Mg}>\mathrm{P}>\mathrm{Fe}>\mathrm{Mn}>\mathrm{Zn}>\mathrm{B}>\mathrm{Cu}$. The export of nutrients ( $\mathrm{g}$ per plant of macronutrients and $\mathrm{mg}$ per plant of micronutrients) by inflorescences was 3.50 of $\mathrm{N}$; 0.296 of $\mathrm{K} ; 0.06$ of $\mathrm{Ca}$; 0.290 of $\mathrm{S}$; 0.032 of $\mathrm{Mg} ; 0.249$ of $\mathrm{P} ; 2.08$ of Fe; 0.375 of $\mathrm{Mn} ; 1.01$ of $\mathrm{Zn} ; 1.45$ of $\mathrm{B}$ and 0.07 of $\mathrm{Cu}$.

Keywords: Brassica oleracea var. botrytis, nutrition, soil.

(Recebido para publicação em 3 de abril de 2008; aceito em 27 de julho de 2009)

(Received in April 3, 2008; accepted in July 27, 2009)

\begin{abstract}
$\mathrm{A}^{\mathrm{a}}$ análise de crescimento de plantas produz conhecimentos de valor prático e informações exatas, referentes ao crescimento e comportamento dos genótipos, que podem ser utilizados pelos produtores, permitindo a escolha da cultivar que melhor se adapte a cada região (Richards, 1993).

Por outro lado, o uso eficiente de nutrientes pelas plantas está relacionado à eficiência na aquisição, no transporte e na utilização desses, que variam em função do genótipo e de fatores ambientais (Baligar \& Fageria, 1999; Marschner, 1995). Diferenças genotípicas na eficiência a alguns nutrientes têm sido atribuídas a uma série de mecanismos, que estão relacionados às características
\end{abstract}

de absorção, translocação e utilização, de forma isolada ou em conjunto (Clark, 1983).

O conhecimento sobre o crescimento das espécies cultivadas permite planejar métodos racionais de cultivo, contribuindo na expressão do potencial genético, além de fornecer dados para construção de modelos matemáticos descritores do crescimento. Os princípios e práticas de análise de crescimento têm como objetivo descrever e interpretar o desempenho das espécies produzidas em ambiente natural ou controlado (Hunt, 1990). Essa técnica fundamenta-se na medida seqüencial do acúmulo de matéria orgânica pela planta, determinada normalmente pela mensuração da massa seca da planta e ou de suas partes.

A couve-flor, que está incluída nas principais brássicas consumidas no Brasil, apresenta alta demanda de nutrientes em curto espaço de tempo. Aliado a isso, as doses de fertilizantes atualmente indicadas subestimam a real necessidade destas culturas para a obtenção de alta produtividade e padrões comerciais (Sturmer et al., 2002).

É de fundamental importância o conhecimento da absorção e do acúmulo de nutrientes nas diferentes fases de desenvolvimento da cultura, permitindo assim, determinar as épocas em que os elementos são mais exigidos e orientar as correções das deficiências 
que venham a ocorrer durante o seu desenvolvimento. É importante ressaltar que as curvas de absorção refletem o que a planta necessita, e não o que deve ser aplicado, uma vez que tem que considerar a eficiência de aproveitamento dos nutrientes, que é variável segundo as condições climáticas, o tipo de solo, o sistema de irrigação, o manejo cultural, entre outros fatores. De modo mais efetivo, essas curvas auxiliam no programa de adubação, principalmente na quantidade dos diferentes nutrientes que devem ser aplicados nos distintos estádios fisiológicos da cultura (Villas Bôas, 2001).

Além disso, a quantidade de nutrientes acumulados nas plantas, principalmente na parte colhida, é importante para se avaliar a remoção desses na área de cultivo, tendo se tornado um dos componentes necessários para as recomendações econômicas de adubação (Vitti et al., 1994).

Devido à escassez de trabalhos relacionados ao crescimento e absorção de nutrientes pela cultura da couve-flor, o presente trabalho teve por objetivo avaliar o crescimento e a quantidade de nutrientes absorvidos e exportados pela couve-flor 'Verona' em Jaboticabal.

\section{MATERIAL E MÉTODOS}

$\mathrm{O}$ experimento foi conduzido em campo, em área pertencente à UNESP em Jaboticabal, cujas coordenadas geográficas são $21^{\circ} 14$ ' $05^{\prime}$ " Latitude Sul, 48 17' 09' longitude Oeste e altitude de $614 \mathrm{~m}$, de 23 de fevereiro a 05 de junho de 2006. Os valores médios para umidade relativa do ar, temperaturas máxima e mínima foram: $75,12 \%, 29^{\circ} \mathrm{C}$ e $16,72^{\circ} \mathrm{C}$ (UNESP, 2008).

A semeadura foi realizada em 23 de fevereiro de 2006, em bandejas de poliestireno expandido com 128 células, preenchidas com substrato à base de casca de pinus. As mudas da cultivar Verona foram transplantadas aos 32 dias após a semeadura, em solo anteriormente preparado e adubado, conforme os resultados da análise do solo e a recomendação de Raij et al. (1997) para a cultura. A análise química do solo apresentou: $\mathrm{pH}$ em $\mathrm{CaCl}_{2}=6,3 ; \mathrm{MO}=18 \mathrm{~g} \mathrm{dm}^{-3} ; \mathrm{P}_{\text {resina }}$
$=54 \mathrm{mg} \mathrm{dm}^{-3} ; \mathrm{K}=2,8 \mathrm{mmol}_{\mathrm{c}} \mathrm{dm}^{-3} ; \mathrm{Ca}$ $=62 \mathrm{mmol}_{\mathrm{c}} \mathrm{dm}^{-3} ; \mathrm{Mg}=30 \mathrm{mmol}_{\mathrm{c}} \mathrm{dm}^{-3}$; $\mathrm{H}+\mathrm{Al}=22 \mathrm{mmol}_{\mathrm{c}} \mathrm{dm}^{-3} ; \mathrm{SB}=95 \mathrm{mmol}_{\mathrm{c}}$ $\mathrm{dm}^{-3} ; \mathrm{T}=117 \mathrm{mmol}_{\mathrm{c}} \mathrm{dm}^{-3} ; \mathrm{V} \%=81$.

$\mathrm{Na}$ adubação de plantio aplicou-se $60 \mathrm{~kg} \mathrm{ha}^{-1}$ de N, $200 \mathrm{~kg} \mathrm{ha}^{-1} \mathrm{P}_{2} \mathrm{O}_{5}$, e 180 $\mathrm{kg} \mathrm{ha}^{-1}$ de $\mathrm{K}_{2} \mathrm{O}$, utilizando sulfato de amônio, superfosfato simples e cloreto de potássio como fontes, respectivamente. Já em cobertura, utilizou-se $100 \mathrm{~kg}$ ha $^{-1}$ de $\mathrm{N}$ e $90 \mathrm{~kg} \mathrm{ha}^{-1}$ de $\mathrm{K}_{2} \mathrm{O}$, divididos em quatro vezes $(15,30,45$ e 55 dias após o transplante), tendo como fontes a uréia e o cloreto de potássio, respectivamente.

As mudas foram transplantadas no espaçamento de $0,5 \mathrm{~m}$ entre plantas e 1 $\mathrm{m}$ entre linhas. $\mathrm{O}$ experimento constou inicialmente de 480 plantas divididas em três blocos. Para cada época de amostragem foram retiradas duas plantas por bloco, tendo sido realizada cinco amostragens da parte vegetativa a cada 14 dias após o transplante e três amostragens das inflorescências a cada 4 dias, após o início de sua formação.

Para a determinação da dinâmica de crescimento da cultura, as plantas amostradas foram cortadas rentes ao solo, divididas em caule, limbo foliar, pecíolo e inflorescência. Em seguida, foi determinada a área foliar (AF) e os órgãos foram secos e pesados. Foram também avaliadas: altura da planta (AP); diâmetro do caule (DC); número de folhas (NF); diâmetro da cabeça (DI); altura da cabeça (AI); massa seca total (MST), das folhas (MSF), do caule (MSC), do pecíolo (MSP) e da inflorescência (MSI).

Posteriormente, foram calculados taxa de crescimento absoluto da cultura $\left(\mathrm{TCA}=\mathrm{P}_{2}-\mathrm{P}_{1} / \mathrm{t}_{2}-\mathrm{t}_{1}\right.$, sendo $\mathrm{P}_{2}$ e $\mathrm{P}_{1} \mathrm{O}$ peso da matéria seca de duas amostragens sucessivas; e $\mathrm{t}_{1}$ e $\mathrm{t}_{2}$ os dias após o plantio); taxa de crescimento relativo (TCR $\left.=\mathrm{L}_{\mathrm{n}} \mathrm{P}_{2}-\mathrm{L}_{\mathrm{n}} \mathrm{P}_{1} / \mathrm{t}_{2}-\mathrm{t}_{1}\right)$, razão de massa de limbo foliar ( $\mathrm{RMLF}=\mathrm{MSF}$ / MST), razão de massa do pecíolo (RMP = MSP/MST), razão de massa do caule $(\mathrm{RMC}=\mathrm{MSC}$ MST), razão de massa da inflorescência (RMI = MSI/MST), área foliar específica $(\mathrm{AFE}=\mathrm{AF} / \mathrm{MSF})$, índice de área foliar $(\mathrm{IAF}=\mathrm{AF} / \mathrm{AS}$, onde AS é a área de solo sombreada pelas folhas), taxa assimilatória líquida (TAL $=\mathrm{P}_{2}-\mathrm{P}_{1} / \mathrm{t}_{2}-\mathrm{t}_{1} \times \mathrm{L}_{\mathrm{n}} \mathrm{AF}_{2}-\mathrm{L}_{\mathrm{n}} \mathrm{AF}_{1} / \mathrm{AF}_{2}-$
$\left.\mathrm{AF}_{1}\right)$ e razão de área foliar $(\mathrm{RAF}=\mathrm{AF} /$ MST), conforme metodologia descrita por Evans (1972) e Benincasa (1986).

As amostras foram lavadas em água deionizada, colocadas para secar em estufa com circulação de ar forçada a $60^{\circ} \mathrm{C}$, até atingirem massa constante e, posteriormente, moídas e submetidas à análise química, segundo método descrito por Malavolta et al. (1997).

As características avaliadas foram submetidas à análise de regressão, sendo considerada como variável independente a idade da planta, expressa em dias, após o transplante. Para os dados do caule, limbo foliar e pecíolo foram utilizadas as funções logísticas, as quais são amplamente empregadas para representar dados empíricos de crescimento de vegetais (Hoffman \& Vieira, 1977), e para os dados das inflorescências foi utilizada função polinomial.

\section{RESULTADOS E DISCUSSÃO}

As inflorescências atingiram o ponto de colheita com altura de 15,72 cm (Figura 1C) e diâmetro de 25,25 cm (Figura 1D).

Os maiores valores de altura $(85,37$ $\mathrm{cm})$, número de folhas $(25,97)$, área foliar $\left(21.897,16 \mathrm{~cm}^{2}\right)$, diâmetro do caule $(33,83 \mathrm{~cm})$, massa fresca das inflorescências $(773,63 \mathrm{~g})$ foram atingidos aos 69 DAT (Figuras 1A, 1B, 2A, 2B e 2C). A produtividade estimada foi de $15.473 \mathrm{~kg} \mathrm{ha}^{-1}$, considerando o estande de 20.000 plantas por hectare, de acordo com Raij et al. (1997).

As plantas apresentaram contínuo acúmulo de massa seca, sendo os maiores valores observados 69 DAT, quando se verificaram para o caule, pecíolo, limbo foliar, cabeça e massa seca total; 23, 48, 127, 90, 283 g (Figura 2D). Até os quarenta dias após o transplante, a planta apresentou pequeno acúmulo de massa seca. Após isso, o acúmulo de massa seca foi mais acentuado. Isso pode ser devido ao menor crescimento ocorrido em virtude das baixas temperaturas ocorridas nas fases iniciais de desenvolvimento da cultura, ou ainda a fatores intrínsecos das brassicáceas, que fazem com que as mesmas apresentem desenvolvimento mais acelerado após 
Tabela 1. Taxa de Crescimento Absoluto (TCA), Taxa de Crescimento Relativo (TCR), Razão de Massa de Limbo Foliar (RMLF), Razão de Massa de Pecíolo (RMP), Razão de Massa do Caule (RMC), Razão de Massa da Cabeça (RMI), Área Foliar Específica (AFE), Índice de Área Foliar (IAF), Taxa Assimilatória Líquida (TAL) e Razão de Área Foliar (RAF), de couve-flor 'Verona', em função da idade da planta (Absolute Growth Rate (TCA), Relative Growth Rate (TCR), Ratio of Leaf Lamina Mass (RMLF), Ratio of Petiole Mass (RMP), Mass Ratio of the Stem (RMC), Ratio of Head Weight ( RMI), Specific Leaf Area (AFE), Leaf Area Index (IAF), Assimilatory Net Rate (TAL) and Leaf Area Ratio (RAF), cauliflower 'Verona', according to the plant age). Jaboticabal, UNESP, 2007.

\begin{tabular}{lcccccccccc}
\hline DAT & $\begin{array}{c}\text { TCA } \\
\left(\mathbf{g ~ d i a}^{-1}\right)\end{array}$ & $\begin{array}{c}\text { TCR } \\
\left(\mathbf{g ~ g ~}^{-1} \mathbf{d i a}^{-1}\right)\end{array}$ & $\mathbf{R M L F}$ & $\mathbf{R M P}$ & $\mathbf{R M C}$ & $\mathbf{R M I}$ & $\begin{array}{c}\text { AFE } \\
\left(\mathbf{c m}^{\mathbf{2}} \mathbf{g}^{-1}\right)\end{array}$ & $\mathbf{I A F}$ & $\begin{array}{c}\text { TAL } \\
\left(\mathbf{g ~ d i a}^{-1} \mathbf{d m}^{-2}\right)\end{array}$ & $\begin{array}{c}\mathbf{R A F} \\
\left(\mathbf{d m}^{\mathbf{2}} \mathbf{g}^{-1} \mathbf{)}\right.\end{array}$ \\
\hline 14 & - & - & 0,603 & 0,300 & 0,097 & - & 246,12 & 0,178 & - & 1,484 \\
28 & 2,168 & 0,128 & 0,676 & 0,226 & 0,098 & - & 186,82 & 0,919 & 0,096 & 1,263 \\
42 & 5,561 & 0,082 & 0,685 & 0,215 & 0,100 & - & 132,68 & 2,076 & 0,078 & 0,909 \\
56 & 4,377 & 0,031 & 0,643 & 0,250 & 0,107 & - & 180,03 & 4,059 & 0,029 & 1,156 \\
69 & 8,573 & 0,038 & 0,453 & 0,168 & 0,083 & 0,296 & 163,23 & 4,243 & 0,041 & 0,739 \\
\hline
\end{tabular}

DAT = Dias Após o Transplante (DAT = Days After Transplant).

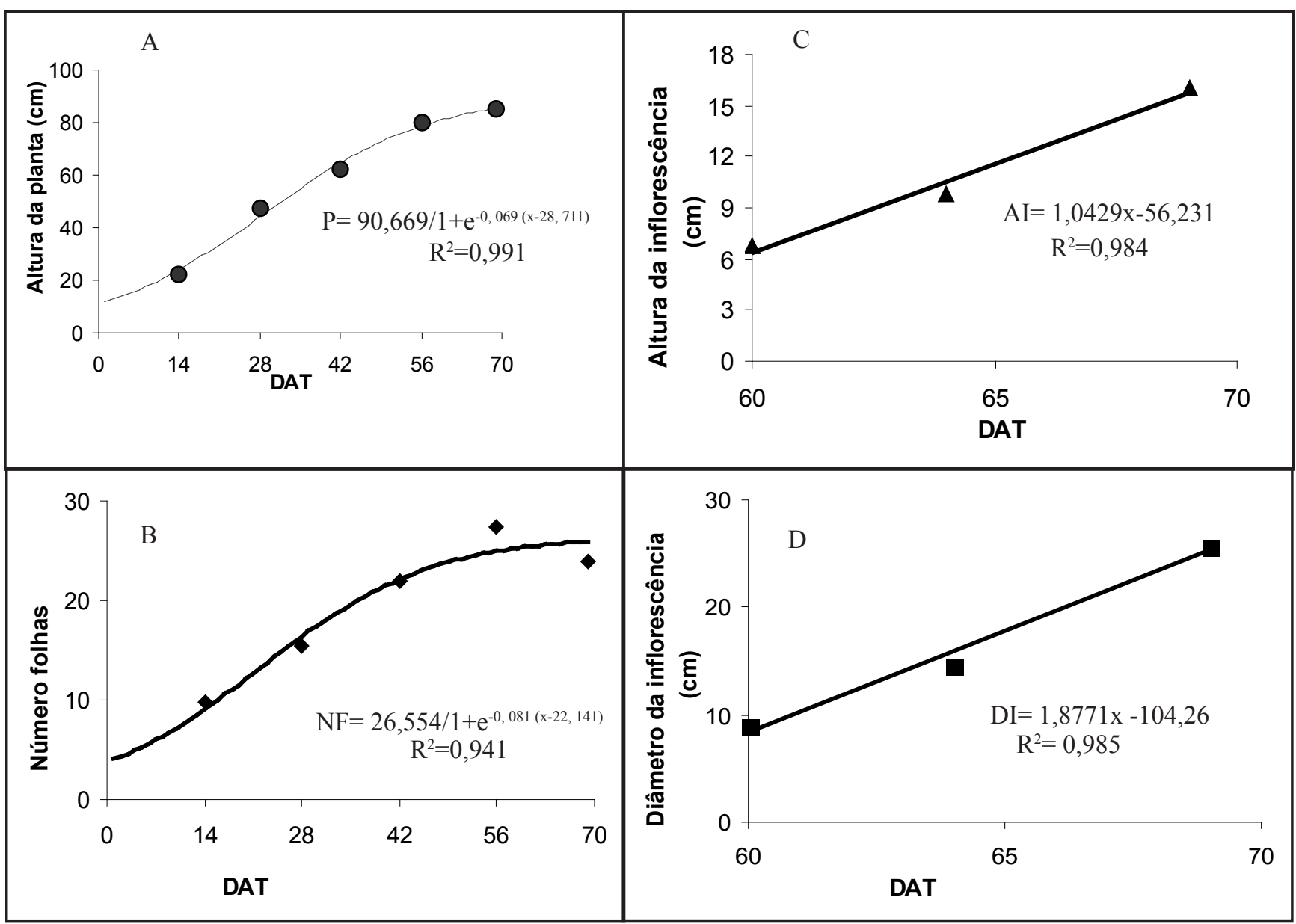

Figura 1. A= Altura da Planta (AP); $\mathbf{B}=$ Número de Folhas (NF); $\mathbf{C}=$ Altura da Inflorescência (AI); $\mathbf{D}=$ Diâmetro da Inflorescência (DI) de couve-flor Verona', em função da idade da planta (A=Plant Height (AP); $\mathbf{B}=$ Number of Leaves (NF); $\mathbf{C}=$ Height of Inflorescence (AI); $\mathbf{D}=$ Inflorescence Diameter (DI) of cauliflower 'Verona', according to plant age). Jaboticabal, UNESP, 2007.

os 40 dias do transplante, como também fora verificado por Charlo et al. (2007) na cultura do brócolis.

A taxa de crescimento absoluto apresentou aumentos contínuos, principalmente dos 56 aos 69 DAT, quando atingiu o seu máximo $\left(8,573\right.$ g planta $^{-1}$ $\left.\operatorname{dia}^{-1}\right)$, devido à formação da inflorescência, a qual apresenta desenvolvimento muito rápido, influenciando significativamente esse índice. A maior taxa de crescimento relativo (TCR) foi aos 28 dias após o transplante com $0,128 \mathrm{~g} \mathrm{~g}^{-1}$ dia (Tabela 1).
A razão de massa de limbo foliar (RMLF) foi maior aos 42 DAT $(0,685)$, ou seja, neste estágio as folhas correspondiam a $68,5 \%$ da massa seca da planta. Após esta época, verificou-se diminuição nesse índice, o qual aos 69 DAT foi de 0,453 , que ocorreu devido 


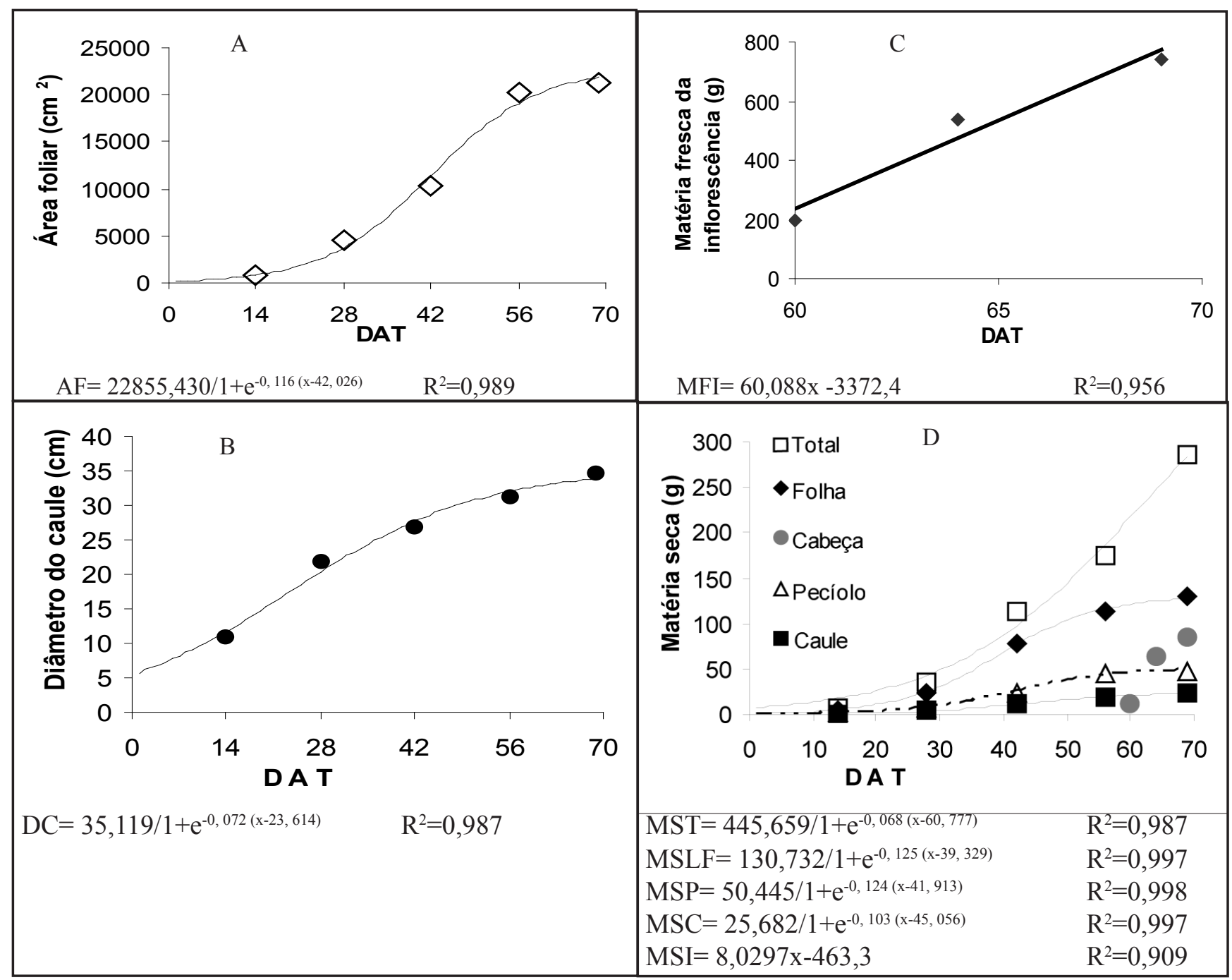

Figura 2. A= Área Foliar (AF); B= Diâmetro do Caule (DC); C= Massa Fresca da Inflorescência (MFI); D - Massa Seca Total (MST), Massa Seca do Limbo Foliar (MSLF), Massa Seca do Pecíolo (MSP), Massa Seca do Caule (MSC) e Massa Seca da Inflorescência (MSI) de couve-flor 'Verona', em função da idade da planta (A= Leaf Area (AF); B=Stem Diameter (DC); C= Fresh Mass of Inflorescence (MFI); $\mathbf{D}=$ Total Dry Mass (MST), Leaf Dry Weight of the Lamina (MSLF), Dry Mass of the Petiole ( CSM), Stem Dry Weight (MSC) and Dry Mass of Inflorescence (MSI), cauliflower 'Verona', according with age of the plant). Jaboticabal, UNESP, 2007.

à formação da inflorescência.

Em virtude da razão de massa de limbo foliar (RMLF) ser maior dos 28 aos 42 DAT, as maiores taxas de crescimento relativo (TCR) foram verificadas nesse período, visto que esses dois parâmetros estão correlacionados, pelo fato de serem as folhas os órgãos fotossinteticamente mais eficientes. À medida que a razão de massa de limbo foliar diminuiu, também ocorreu diminuição na taxa de crescimento relativo.

Aos 14 DAT, ocorreu o maior valor de razão de massa do pecíolo (RMP), sendo o pecíolo das folhas correspondente a $30 \%$ da massa seca da planta. Já a razão de massa de caule (RMC) apresentou contínuo aumento até os 56
DAT, quando representava $10,7 \%$ da massa seca da planta (Tabela 1).

Para a razão de massa da cabeça (RMI) esse órgão correspondeu a 29,6\% da massa seca da planta aos 69 DAT. Ele apresentou rápido crescimento, visto que na avaliação feita aos 56 DAT este não estava visível, e em apenas 13 dias já se apresentava no ponto de colheita, influenciando assim, a taxa de crescimento absoluto da planta.

A maior área foliar específica (AFE) foi alcançada aos 14 DAT com 246,12 $\mathrm{cm}^{2} \mathrm{~g}^{-1}$, decrescendo até os 42 DAT e com posterior aumento aos 56 DAT, voltando a diminuir aos 69 DAT. Esse decréscimo de valores da área foliar específica é devido ao fato de que nos estádios iniciais da couve-flor há maior desenvolvimento do limbo foliar, diminuindo à medida que o caule e a inflorescência se desenvolvem, sendo resultante da redução ou paralisação na expansão foliar (Negreiros, 1995), incremento nas taxas de senescência e abscisão das folhas (Scott \& Batchelor, 1979), ou desenvolvimento de outros órgãos da planta.

O índice de área foliar (IAF), relação entre área foliar total e área sombreada, aumentou continuamente, sendo o maior valor observado aos 69 DAT $(4,243)$. À medida que a área foliar cresce, o IAF também aumenta, até atingir um valor em que o auto-sombreamento passa a ser prejudicial. Aquino et al. (2005) verifi- 


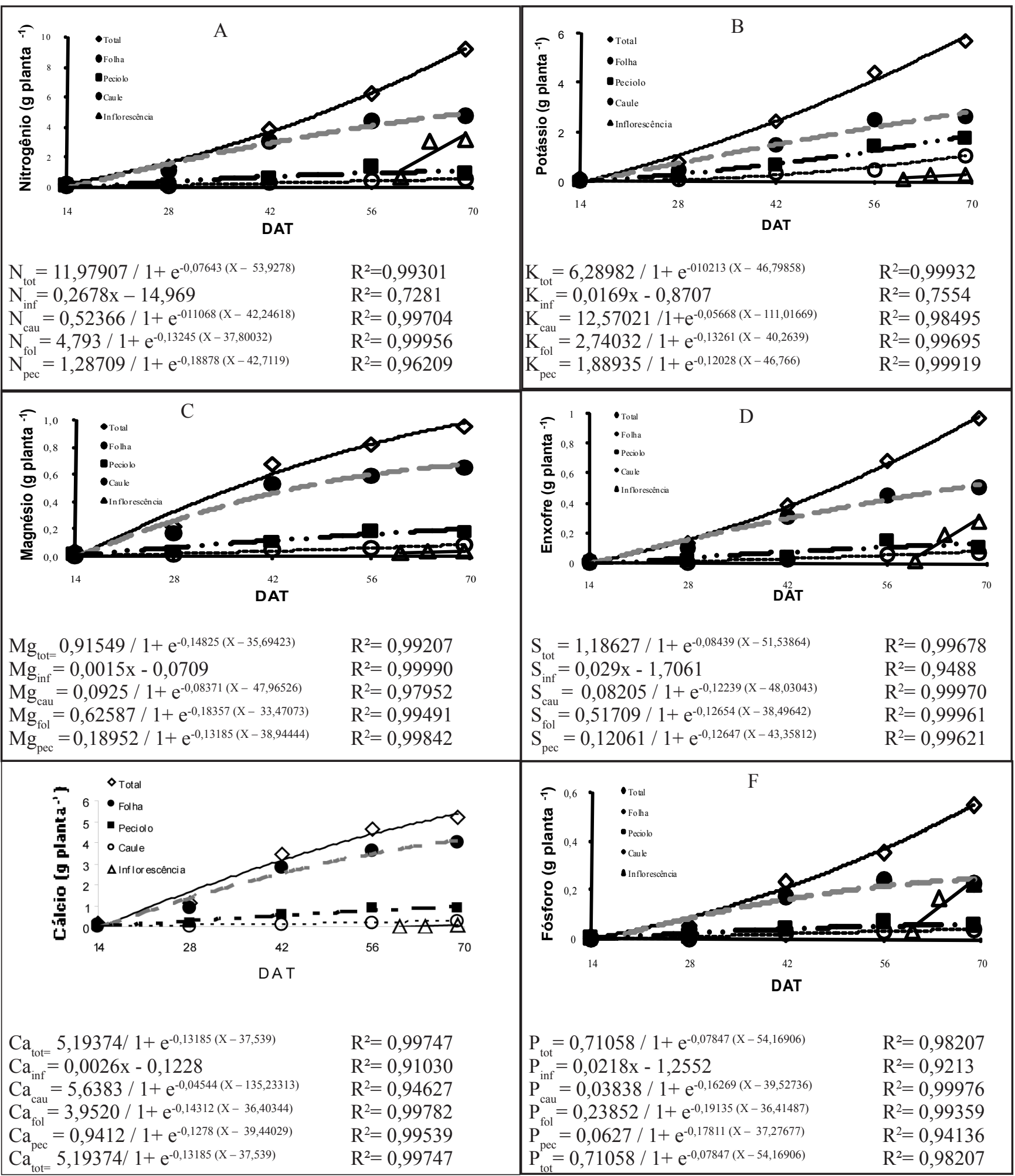

Figura 3. A= Curvas de Acúmulo de Nitrogênio ( $\mathrm{N}) ; \mathbf{B}=$ Curvas de Acúmulo de Potássio $(\mathrm{K})$; $\mathbf{C}=$ Curvas de Acúmulo de Magnésio $(\mathrm{Mg})$; $\mathrm{D}=$ Curvas de Acúmulo de Enxofre $(\mathrm{S}) ; \mathbf{E}=$ Curvas de Acúmulo de Cálcio $(\mathrm{Ca}) ; \mathbf{F}=$ Curvas de Acúmulo de Fósforo $(\mathrm{P})$ na cultura da couveflor 'Verona', em função da idade da planta $(\mathbf{A}=$ Curves of Accumulation of Nitrogen $(\mathrm{N}), \mathbf{B}=$ Curves of Accumulation of Potassium $(\mathrm{K}), \mathbf{C}=$ Curves of Accumulation of Magnesium (Mg); $\mathrm{D}=$ Curves of Accumulation of Sulphur $(\mathrm{S})$; $\mathbf{C}=$ Curves of Accumulation of Calcium $(\mathrm{Ca}) ; \mathbf{F}=$ Curves of Accumulation of Phosphorus (P) in the culture of cauliflower 'Verona', depending on plant age). Jaboticabal, UNESP, 2007.

caram para a cultura do repolho que o índice de área foliar que proporcionou a maior produção de cabeças foi de 2,88 $\mathrm{cm}^{2} \mathrm{~cm}^{-2}$. Por se tratarem de culturas da mesma família, espera-se que o índice de área foliar adequado para a cultura da couve-flor seja semelhante ao do repolho.
A maior taxa assimilatória líquida (TAL) foi observada aos 28 DAT $(0,096$ $\left.\mathrm{g} \mathrm{dia}{ }^{-1} \mathrm{dm}^{-2}\right)$, decrescendo até aos 56 DAT $\left(0,029 \mathrm{~g} \mathrm{dia}^{-1} \mathrm{dm}^{-2}\right)$ e aumento aos 
69 DAT $\left(0,041 \mathrm{~g} \mathrm{dia}^{-1} \mathrm{dm}^{-2}\right)$. Além da ontogenia, a taxa assimilatória líquida é dependente da radiação solar, das condições internas da planta, do próprio índice de área foliar e do balanço hídrico. Sendo assim, há uma tendência de diminuição da taxa assimilatória líquida ao longo do desenvolvimento da cultura, visto que o sombreamento mútuo pelo arranjo foliar conduz a uma pobre penetração de luz no dossel. Portanto, a taxa assimilatória líquida decresce com aumento no índice de área foliar em condições de campo (Tsuno \& Fujise, 1962), mesmo que ocorra incremento na área foliar, conforme ocorreu no presente experimento.

Houve diminuição contínua dos valores de razão de área foliar, com exceção aos 56 DAT. Aos 14 DAT este índice era de $1,484 \mathrm{dm}^{2} \mathrm{~g}^{-1}$, chegando a 0,739 $\mathrm{dm}^{2} \mathrm{~g}^{-1}$ aos 69 DAT. A diminuição na razão de área foliar indica decréscimo na quantidade de assimilados destinados às folhas e pode ocasionar redução na taxa de crescimento relativo (Nilwik, 1981), como ocorreu no presente trabalho.

$\mathrm{O}$ acúmulo de nitrogênio $(\mathrm{N})$ foi lento até os 28 DAT (Figura 3A), quando verificou-se acúmulo de 1,03 g planta $^{-1}$ nos limbos foliares; $0,09 \mathrm{~g}_{\text {planta }}{ }^{-1}$ no caule e $0,07 \mathrm{~g}$ planta $^{-1}$ nos pecíolos. No período entre 28 e 56 DAT ocorreu a maior exigência por esse nutriente por parte das folhas em detrimento ao caule e aos pecíolos, com acúmulo de 3,$37 ; 0,34$ e 1,11 g planta $^{-1}$, respectivamente. No período de 56 aos 69 DAT, a quantidade acumulada de $\mathrm{N}$ nas folhas, no caule e nos pecíolos estabilizou-se, devido à translocação desse nutriente às inflorescências. Nas inflorescências, o acúmulo de $\mathrm{N}$ foi contínuo durante seu desenvolvimento, apresentando 3,50 g planta $^{-1}$ de $\mathrm{N}$ aos 69 DAT. Considerandose 20.000 plantas por hectare, a exportação de $\mathrm{N}$ nessa situação seria de 70 kg por hectare. O total de $\mathrm{N}$ acumulado pela planta aos 69 DAT foi de $9 \mathrm{~g}$, o que correspondeu ao acúmulo de 183 $\mathrm{kg} \mathrm{ha}^{-1}$ de N.

O potássio foi o segundo macronutriente mais acumulado pela planta com o máximo de 5,81 $\mathrm{g} \mathrm{planta}^{-1}$ aos 69 DAT, sendo que a maior exigência, para os limbos foliares e pecíolos, ocorreu no período de 28 a 56 DAT (Figura 3B).
Para o caule, a maior exigência deu-se dos 42 aos 69 DAT, acumulando nesse período 0,82 g planta $^{-1}$, ou seja, $76,42 \%$ do total acumulado pelo caule. As participações do limbo foliar, pecíolos, caule e inflorescências foram respectivamente, de: $46,16 \% ; 30,43 \% ; 18,31 \%$ e $5,10 \%$ do total acumulado pela planta.

De acordo com Raij et al. (1997), nas adubações de plantio e cobertura é aplicada a relação N:K de 1,19:1. De acordo com os dados obtidos no presente trabalho, no entanto, a relação de absorção e acúmulo de $\mathrm{N}: \mathrm{K}$ é de 1,58:1, o que sugere que a relação $\mathrm{N}: \mathrm{K}$ para os novos híbridos de couve-flor que são lançados no mercado, pode estar inadequada.

A extração e a exportação de $\mathrm{N}$ e $\mathrm{K}$ foram, respectivamente, de 183,69 $\mathrm{kg} \mathrm{ha}^{-1}$ e $70 \mathrm{~kg} \mathrm{ha}^{-1}$. Entretanto, a aplicação desse elemento correspondeu a $160 \mathrm{~kg} \mathrm{ha}^{-1}$, indicando que parte do $\mathrm{N}$ foi proveniente da matéria orgânica do solo para atender à exigência da planta. Esses resultados indicam que a aplicação orgânica é uma prática importante na manutenção da fertilidade do solo e no fornecimento de nitrogênio.

Para o cálcio, terceiro macronutriente mais acumulado pelas plantas, a maior demanda ocorreu no período de 28 a 56 DAT. Do total de Ca acumulado pela planta, os limbos foliares foram responsáveis por $75,92 \%$, os pecíolos por $17,84 \%$, caule por $5,13 \%$ e a inflorescência por apenas 1,11\%. Esse comportamento do $\mathrm{Ca}$ se deve à sua baixa mobilidade no floema, não ocorrendo sua redistribuição das folhas para outros órgãos como as inflorescências (Malavolta et al., 1997). No período de 56 a 69 DAT, a quantidade de $\mathrm{Ca}$ acumulado nas folhas, caule e pecíolos atingiu, respectivamente: 0,$19 ; 0,11 \mathrm{e}$ 0,08 g planta $^{-1}$. Nas inflorescências, o acúmulo foi crescente ao longo de todo o desenvolvimento deste órgão, com total acumulado de $0,06 \mathrm{~g} \mathrm{planta}^{-1}$ de $\mathrm{Ca}$ (Figura 3E). Da quantidade de 103,2 kg de $\mathrm{Ca}$ acumulados pela planta, apenas 1,2 $\mathrm{kg}$ foi exportado pelas inflorescências, sendo o restante reincorporado ao solo pelos restos de cultura, principalmente pelas folhas.

O total acumulado de $\mathrm{Mg}$ na planta foi de $0,92 \mathrm{~g} \mathrm{planta}^{-1}$, tendo ocorrido a maior demanda no período de 42 a 56
DAT (Figura 3C). As participações do caule, pecíolos, folhas e inflorescências foram de $67,75 \% ; 20,16 \% ; 8,55 \%$ e $3,54 \%$, respectivamente. As quantidades de $\mathrm{Mg}$ acumuladas no caule e pecíolos foram muito semelhantes, sendo constante durante todo o ciclo da cultura. Os limbos foliares apresentaram acúmulo muito rápido no início do desenvolvimento (até 42 DAT) e após esse período (42 aos 69 DAT) a taxa de acúmulo de $\mathrm{Mg}$ pelos limbos foliares foi baixa, fazendo com que, neste período, acumulasse $0,11 \mathrm{~g}$ planta $^{-1}$ de $\mathrm{Mg}$. As inflorescências apresentaram maior demanda no período de 64 a 69 DAT, e, ao final deste período, o acúmulo de $\mathrm{Mg}$ correspondeu a $75,13 \%$ do total acumulado nas inflorescências ao final do ciclo. Aos 69 DAT, as inflorescências apresentaram acúmulo de 0,032 g planta $^{-1}$ de $\mathrm{Mg}$, o que correspondeu à exportação de $0,65 \mathrm{~kg} \mathrm{ha}^{-1}$.

$\mathrm{O}$ enxofre, assim como o $\mathrm{Ca}$, apresentou maior acúmulo nos limbos foliares, atingindo valor máximo de 0,51 g planta $^{-1}$ aos 69 DAT (50,97\% do total acumulado pela planta). As demais partes da planta, ou seja, inflorescência, pecíolos e caule tiveram acúmulos máximos de, respectivamente, 0,29 g planta $^{-1}$; 0,12 e 0,07 g planta $^{-1}(29,29 \% ; 12,67 \%$ e $7,07 \%$ do total da planta, respectivamente). Nos limbos foliares, assim como no caule e pecíolos, a taxa de acúmulo foi baixa até os 28 DAT, com acúmulo de, respectivamente, 0,11;0,006 e $0,01 \mathrm{~g} \mathrm{planta}^{-1}$ (Figura 3D). Após esse período (28 aos $56 \mathrm{DAT}$ ) houve rápido incremento nas taxas de acúmulo de enxofre nas respectivas partes da planta, e somente no final do ciclo (56 aos 69 DAT) o acúmulo voltou a ser lento, em detrimento ao rápido desenvolvimento e demanda deste nutriente pela inflorescência, que exportou $5,8 \mathrm{~kg} \mathrm{ha}^{-1}$ deste nutriente.

$\mathrm{O}$ acúmulo de fósforo atingiu valor máximo estimado de $0,59 \mathrm{~g}_{\text {planta }}{ }^{-1}$ aos 69 DAT, sendo que as folhas, inflorescências, pecíolos e caule contribuíram com respectivamente, 40,51\%, 42,37\%, $10,64 \%$ e $6,48 \%$ (Figura 3F). As folhas e as inflorescências apresentaram, aproximadamente, a mesma quantidade de $\mathrm{P}$ acumulado, com valores no final do ciclo de 0,24 e $0,25 \mathrm{~g}_{\text {planta }}{ }^{-1}$, respec- 


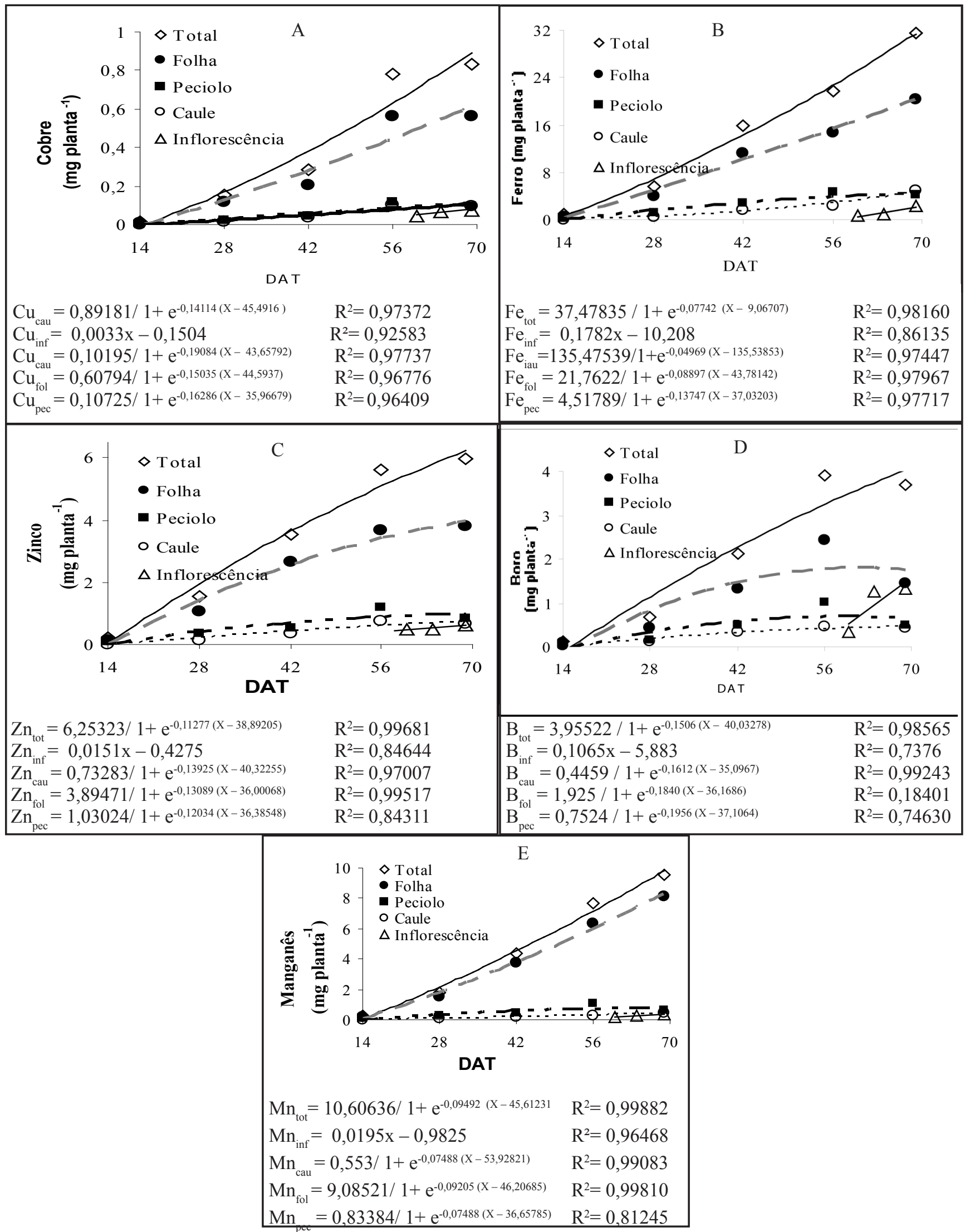

Figura 4. $\mathbf{A}=$ Curvas de Acúmulo de Cobre $(\mathrm{Cu}) ; \mathbf{B}=$ Curvas de Acúmulo de Ferro $(\mathrm{Fe}) ; \mathbf{C}=$ Curvas de Acúmulo de Zinco (Zn); $\mathbf{E}=$ Curvas de Acúmulo de Boro (B); $\mathbf{C}=$ Curvas de Acúmulo de Manganês (Mn) na cultura da couve-flor 'Verona', em função da idade da planta (A= Curves of Accumulation of Copper $(\mathrm{Cu}) ; \mathbf{B}=$ Curves of Accumulation of Iron $(\mathrm{Fe}) ; \mathbf{C}=$ Curves of Accumulation of Zinc $(\mathrm{Zn})$; $\mathbf{E}=\mathrm{Curves}$ of Accumulation of Boron (B); $\mathbf{C}=$ Curves of Accumulation of Manganese (Mn); of the culture of cauliflower 'Verona', according to the plant age). Jaboticabal, UNESP, 2007. 
tivamente. Portanto, a exportação de fósforo pelas inflorescências foi de 5 $\mathrm{kg}$ de $\mathrm{Pha}^{-1}$.

No caule e nos pecíolos, o acúmulo de $\mathrm{P}$ foi lento até os 28 DAT $(0,005$ e $0,01 \mathrm{~g} \mathrm{planta}^{-1}$, respectivamente). A maior exigência de $\mathrm{P}$ pelo caule ocorreu dos 28 aos 56 DAT, com acúmulo estimado de 0,03 g planta $^{-1}$, cerca de $80,90 \%$ do total acumulado pelo caule. Para os pecíolos, a maior exigência ocorreu dos 28 aos 50 DAT, com acúmulo estimado de 0,05 g planta $^{-1}(74,72 \%$ do total acumulado pelo pecíolo) (Figura 3F).

Quanto ao acúmulo de micronutrientes nas diferentes partes da planta, a quantidade total acumulada de cobre $(\mathrm{Cu})$ foi de $0,87 \mathrm{mg} \mathrm{planta}^{-1}$, sendo que o caule, os limbos foliares e os pecíolos atingiram, respectivamente, 0,$10 ; 0,59$ e $0,11 \mathrm{mg}$ planta $^{-1}$. (Figura 4A). As inflorescências apresentaram acúmulo de $0,07 \mathrm{mg}$ planta $^{-1}(8,04 \%$ do total acumulado) o que corresponde à remoção de $1,4 \mathrm{~g} \mathrm{ha}^{-1}$ de $\mathrm{Cu}$ por este órgão, sendo o micronutriente exportado em menor quantidade pela cultura. $\mathrm{O}$ acúmulo de $\mathrm{Cu}$ no caule, nos pecíolos e nas folhas foi semelhante, sendo lento até os 28 DAT, com acúmulos de 0,005; 0,02 e $0,05 \mathrm{mg} \mathrm{planta}^{-1}$, respectivamente. No período dos 28 aos 56 DAT, houve a maior demanda desse micronutriente e, após os 56 DAT, a quantidade acumulada no pecíolo e no caule foi estabilizada.

$\mathrm{O}$ ferro, micronutriente mais acumulado que os demais $\left(31,01 \mathrm{mg}\right.$ planta $\left.^{-1}\right)$, apresentou acúmulo contínuo e crescente para caule e limbo foliar durante todo ciclo da cultura, atingindo 4,80 e 19,67 mg planta ${ }^{-1}$ aos 69 DAT, respectivamente (Figura 4B). O acúmulo de ferro no pecíolo foi lento até os 28 DAT (1,01 mg planta $\left.{ }^{-1}\right)$. Dos 28 até aos 56 dias houve cerca de $71,59 \%$ do total acumulado pelos pecíolos e dos 56 aos 69 DAT, houve tendência de estabilização, atingindo o máximo de $4,46 \mathrm{mg}$ planta $^{-1}$ de Fe. $\mathrm{O}$ acúmulo máximo de Fe pelas inflorescências foi de 2,08 mg planta $^{-1}$ aos 69 DAT, o que correspondeu a $6,73 \%$ do total acumulado pela planta, e exportação de $41,6 \mathrm{~g} \mathrm{ha}^{-1} \mathrm{de} \mathrm{Fe}$.

O manganês, apesar de ser o segundo micronutriente mais acumulado pela planta $\left(9,71 \mathrm{mg}\right.$ planta $\left.^{-1}\right)$, foi o que apresentou a menor porcentagem de exportação em relação ao total acumulado $(3,87 \%)$ (Figura 4E). O caule e as folhas apresentaram acúmulos semelhantes, de forma lenta até os 28 DAT $(0,07$ e $1,43 \mathrm{mg}$ planta $^{-1}$, respectivamente, para caule e folhas) e posteriormente rápida, correspondendo ao período de maior acúmulo. A taxa de acúmulo para os pecíolos até os 28 DAT também foi lenta $\left(0,18 \mathrm{mg}\right.$ planta $\left.{ }^{-1}\right)$, posteriormente (28 aos 50 DAT) esta taxa aumentou significativamente $\left(0,55 \mathrm{mg}_{\text {planta }}{ }^{-1}\right)$, estabilizando-se somente após esse período.

$\mathrm{O}$ acúmulo total de zinco pela cultura foi de $6,19 \mathrm{mg} \mathrm{planta}^{-1}$. O caule $(0,72$ $\mathrm{mg}$ planta $\left.^{-1}\right)$ e limbos foliares $(3,84 \mathrm{mg}$ planta $\left.^{-1}\right)$ apresentaram características semelhantes, tendo acúmulo lento até os 28 DAT de $15,52 \%$ e $26,32 \%$ pelo caule e folhas, respectivamente (Figura 4D). Dos 28 aos 56 DAT, foi o período de maior acúmulo deste nutriente por estes órgãos, sendo que do total acumulado $76 \%$ e $68,11 \%$ do total, para o caule e folhas, respectivamente. A partir desse período, o acúmulo de $\mathrm{Zn}$ pelas respectivas partes da planta voltou a ser lento $\left(0,06\right.$ e $0,21 \mathrm{mg}$ planta $^{-1}$ para caule e folhas, respectivamente). Para os pecíolos e inflorescências, o acúmulo foi constante e os seus valores máximos foram de 0,61 e $1,01 \mathrm{mg}$ planta $^{-1}$, respectivamente (Figura 4C). Portanto, foi exportado pelas inflorescências 20,2 $\mathrm{g} \mathrm{ha}^{-1} \mathrm{de} \mathrm{Zn}$.

$\mathrm{O}$ acúmulo total de boro na planta foi de 4,57 mg planta-1(Figura 4D), sendo que a maior parte $(42,01 \%)$ foi acumulada pelas folhas. Verifica-se que no período dos 28 aos 50 DAT as folhas, pecíolos e caule apresentaram o maior acúmulo, ou seja, 74,70; 78,30 e $67,85 \%$, respectivamente do total acumulado. Posteriormente (50 aos 69 DAT) houve uma forte tendência de estabilização, sendo esse período o de menor acúmulo. Isso ocorreu, pois coincide com a época de formação das inflorescências, que exigem uma grande demanda desse nutriente.

As plantas apresentaram crescimento e acúmulo de massa seca contínuos. Do início da formação da inflorescência até a colheita, esta foi o principal dreno da planta. A ordem decrescente dos nutrientes acumulados pela cultura foi: $\mathrm{N}>\mathrm{K}>\mathrm{Ca}>\mathrm{S}>\mathrm{Mg}>\mathrm{P}>\mathrm{Fe}>\mathrm{Mn}>\mathrm{Zn}>\mathrm{B}>\mathrm{C}$ u. A exportação de macronutrientes ( $\mathrm{g}$ planta $^{-1}$ ) e micronutrientes ( $m g$ planta ${ }^{-1}$ ) pelas inflorescências foi de: 3,50 de N; 0,296 de K; 0,06 de Ca; 0,290 de S; 0,032 de Mg; 0,249 de P; 2,08 de Fe; 0,375 de $\mathrm{Mn} ; 1,01$ de Zn; 1,45 de B e 0,07 de $\mathrm{Cu}$.

\section{REFERÊNCIAS}

AQUINO LA; PUIATTI M; PEREIRA PRG; PEREIRA FHF; CASTRO MRS; LADEIRA IR. 2005. Características produtivas do repolho em função de espaçamentos e doses de nitrogênio. Horticultura Brasileira 23: 266-270.

BALIGAR VC; FAGERIA NK. 1999. Plant nutrient efficiency: forward the second paradigm. In: SIQUEIRA J; MOREIRA FMS; LOPES AS; GUILHERME LRG; FAQUIN V; FURTINI NETO AE; CARVALHO JG. Inter-relação fertilidade, biologia do solo e nutrição de plantas. Lavras: UFLA/DCS/ SBCS. p. 183-204.

BENINCASA MMP. 1986. Análise de crescimento de plantas. Jaboticabal: Funep. 42p.

CASTRO MM. 2006. Desempenho de sementes de couve-flor em função de níveis de vigor e resposta à aplicação de nitrogênio. Ilha Solteira: UNESP-Campus de Ilha Solteira. 49 f. (Tese mestrado).

CHARLO HCO; VARGAS PF; CASTOLDI R; OLIVEIRA SF; BRAZ LT. 2007. Análise de crescimento, distribuição de matéria seca e produção de couve brócolos de cabeça única 'Legacy'. In: CONGRESSO BRASILEIRO DE OLERICULTURA, 47. Resumos... Porto Seguro. Horticultura Brasileira. (CDROOM).

CLARK RB. 1983. Plant genotype differences in the uptake, translocation, accumulation and use of mineral elements required for plant growth. In: SARIC MR; LONGHMANN BC (eds). Genetic aspects of plant nutrition. The Hague: Martinus Nighoff. p. 49-70.

EVANS GC. 1972. The quantitative analysis of plant growth. Oxford: Blackwell Scientific Publications. p.734.

FILGUEIRA FAR. 2000. Novo Manual de Olericultura. Viçosa: UFV. 402p.

TSUNO Y; FUJISE K. 1962. Study on the dry matter production of sweet potato. I Photosynthesis in the sweet potato with special reference to measuring of intact leaves under natural conditions. Proceedings Crop Science Society of Japan 13:145-149.

GODOY MC; CARDOSO AII. 2005. Produtividade da couve-flor em função da idade de transplantio das mudas produzidas e tamanhos de células na bandeja. Horticultura Brasileira 23: 837-840.

HOFFMANN R; VIEIRA S. 1977. Análise de regressão - uma introdução à econometria. São Paulo: HUCITEC-EDUSP. 399 p.

HUNT R. 1990. Basic growth analysis. London: 
Unwin Hyman. 112 p.

MALAVOLTA E; VITTI GC; OLIVEIRA SA. 1997. Avaliação do estado nutricional das plantas: principios e aplicações. 2. ed. Piracicaba: POTAFOS. 319 p.

MARSCHNER, H. 1995. Mineral nutrition of higher plants. San Diego: Academic Press. $889 \mathrm{p}$.

NEGREIROS MZ. 1995. Crescimento, partição de matéria seca, produção e acúmulo de macronutrientes de plantas de pimentão (Capsicum annum L.) em cultivo podado e com cobertura morta. Viçosa: UFV. 187p. (Tese doutorado).

NILWIK HJM. 1981. Growth analysis of sweet pepper (Capsicum annum L.) and interacting effects of irradiance, temperature and plant age in controlled conditions. Annals of Botany 48: 137-145.

PEREIRA AR; MACHADO EC. 1987. Análise quantitativa do crescimento de comunidade vegetais. Campinas: IAC. 33p. (Boletim Técnico, 114).

RAIJ BV; CANTARELLA H; QUAGGIO JA; FURLANI AMC. (Ed.). 1997. Recomendações da adubação e calagem para o Estado de São Paulo. 2. ed. Campinas: IAC. 285 p. (Boletim Técnico, 100).

RICHARDS FJ. 1993. The quantitative analysis of growth. In: SHARMA BD; KAUL HN; SINGH M. Growth analysis of potato varieties in autumn in subtropical conditions. New Botanist: Lucknow, v. 20, n. 54, p. 55-69.

SCOTT HD; BATCHELOR JT. 1979. Dry weight and leaf area production rates of irrigated determinate soybeans. Agronomy Journal 71: 776-782.

STURMER SL; BARTZ HR; TREVISAN JN; MARTINS GAK; HOLZSCHUH MJ; TREVISAN BG. 2002. Validação das recomendações de adubação nitrogenada para uma sucessão de brassicáceas em Planossolo Hidromórfico distrófico arênico da região central do RS. In: FERTIBIO 2002. Anais.. Rio de Janeiro: Fertibio (CD-ROM).

UNESP. 2008. Dados meteorológicos. $<$ Disponível em: http://www.exatas.fcav.unesp.br/estacao/ est tab meteor 01 02.htm $>$ Acessado em 12 de dezembro de 2008 .

VILLAS BÔAS RL. 2001.Doses denitrogênio para pimentão aplicadas de forma convencional e através da fertirrigação. Botucatu. UNESP. $123 \mathrm{p}$. (Tese livre docência).

VITTI GC; BOARETTO AE; PENTEADO SR. 1994. Fertilizantes e fertirrigação. In: SIMPÓSIO BRASILEIRO SOBRE FERTILIZANTES FLUÍDOS, 1. Anais... Piracicaba: Associação Brasileira para Pesquisa da Potassa e do Fosfato. p. 261-280. 